\title{
Ett inställt bröllop och två ljusstakar
} av tenn

\author{
Om en bröllopsdikt av Jacob Frese
}

UNDER TIDIGMODERN TID SKREV man gärna och ofta uppvaktningar i bunden form med anledning av skilda tillfällen i en människas liv eller i samhällets. Den som fattade pennan kunde vara en ung student i behov av goda kontakter, en ansedd man i staten eller en av samtiden värderad skald. ${ }^{1}$ Det poetiska hantverket var spritt, i den manliga skaran kunde en och annan kvinna smyga sig in och färdigheten uppövades om det ville sig väl till god konst. Dessa tillfällesdikter trycktes, spreds, lästes och samlades i hemmens bibliotek. En och annan skald lät dem också ingå i en samlingsvolym vid sidan av kärlekspoesi och andliga visor, värderade också de.

Så var fallet med Jacob Frese som kom att bli en uppburen skald och ett namn i vår litteraturhistoria. $\mathrm{Om}$ en av hans tidigare tillfällesdikter skall denna essä handla, en uppvaktning på vers med anledning av ett bröllop som aldrig blev av. Först vill jag presentera de tre personer vi möter i denna berättelse, nämligen Jacob Frese, skalden, och de båda som var på väg att vigas samman, Sven Leijonmarck och Margareta Spieker. Därpå nämner jag något om dikten som säkerligen var tänkt att roa gästerna vid bröllopsfesten, innan jag redogör för det vi vet om omständigheterna kring trolovningens upphävande. Sist vill jag säga något om hur det gick för dessa tre. Rubrikens tennljusstakar kommer så småningom in i bilden. Men först alltså något om bröllopsdiktens skald och dess adressater.

I. Våren 2017 var detta slags diktning föremål för ett symposium i Lund. Föreläsningarna från dessa dagar ingår i Arne Jönsson, Valborg Lindgärde, Daniel Möller \& Arsenii Vetushko-Kalevich (red.), Att dikta för livet, döden och evigheten. Tillfällesdiktning under tidigmodern tid, Göteborg \& Stockholm: Makadam förlag 2020. Här har aspekten inställda tillfällen inte behandlats. 


\section{Jacob Frese, Margareta Spieker och Sven LEIJONMARCK. EN KORT PRESENTATION}

Jacob Frese (I69I-I729) föddes i Viborg i en tysk köpmannasläkt som etablerat sig i staden under r60o-talet. ${ }^{2}$ I mars 1703 blev han inskriven i Viborgs nation vid Kungliga Akademien i Ảbo tillsammans med de äldre bröderna Hans och Mårten. Den första tryckta dikt som finns bevarad av den blivande skaldens hand är riktad till lektorn vid gymnasiet i Viborg, Carolus Laurbecchius och Margareta Elisabet Flachsenia vid deras bröllop 1708. ${ }^{3}$ När handelsmannen Johan Fredrich Bagge den 23 januari 17ı firade bröllop med Elsa Magdalena Spieker förärades brudparet ett versifierat samtal om äktenskapet mellan de fingerade gestalterna Philogamos, äktenskapets förespråkare, och Atisandros som här förordar ett liv som ogift. ${ }^{4}$ Denna dikt mynnar ut inte bara i en lyckönskan till brudgummen som nu fătt en dotter $i$ huset Spieker till hustru, utan även i en hyllning av hennes familj:

2. Om Jacob Frese, se framför allt Arvid Hultin, "Lefnadsteckning", Valda skrifter af Jakob Frese med en teckning af hans lefnad och skaldskap, Helsingfors: Svenska litteratursällskapet i Finland I9o2, s. I-CXIX; Sven-Christer Swahn, Jacob Frese. Frän en finlandssvensk I70o-talsförfattares liv och dikt, Lund: Läromedelsförlagen I971; Sven-Christer Swahn,"Jacob Frese", Svenskt Biografiskt Lexikon I6, Stockholm I964-I966, s. 493.

3. Laurbecchius/Flachsenia, Verser över enskilda (fol.), I7ı, Kungliga biblioteket, Stockholm (KB). Då Viborg erövrades av ryssarna den 13 juni I7ı, flydde Laurbecchius (1677-I723) och kom efter ett par år i Åbo till Sverige och en tjänst som lektor i Linköping där han dog I723. Margareta Flachsenia överlevde maken, gifte om sig och dog först 1753. Om Viborg som en viktig stad för handel och kulturmöten vid denna tid, se Marika Tandefelt, "Fyra språk på en marknad", Marika Tandefelt (red.), Viborgs fyra språk under sju sekel, Helsingfors: Schildts 2002, s. II-67.

4. Bagge/Spieker, Verser över enskilda (fol.), r7ıo, Kungliga biblioteket, Stockholm (KB), tryckt i Hultin (utg.), Valda skrifter af Jakob Frese, s. I69. Bagge var prästson, född i Marstrand I682, bosatt i Örebro I720 där han blev rådman och där han dog I740. Efter hustruns död gifte han om sig 1732 enligt en bevarad dikt till detta bröllop (KB, fol): Bagge/Perman, Verser över enskilda (fol.), r732, Kungliga biblioteket, Stockholm (KB). Jacob Cats dikt Maegdhen-Plicht (I618) torde ha inspirerat Frese till bröllopsdikten I7ı om äktenskapets väl och ve. Den fanns vid denna tid $i$ en översättning av Lars Johanson Lucidor och bearbetad av Nils Keder. Se Lars Johanson (Lucidor), Samlade dikter, Svenska författare. Ny serie, utgiven av Stina Hansson, Stockholm I997, s. 399. 
Ja hela thet Förnäma Huus/

Är lijk en Lyckta och ett Lius/

Med några andra få i rad/

För Hela hela Åbo Stad.

De uppskattande orden hade fog för sig. Mer om det nedan.

Jacob Frese tycks ha kommit till Stockholm någon gång detta år I7Io, under stora nordiska kriget (I700-I72I) då ryssarna belägrade och efter några månader intog hans hemstad Viborg. Det var, för att citera Arvid Hultin,"tidens stormar och den stora ofredens fasor, som drefvo Frese liksom så många andra af hans samtida i flykt från sitt af fiendens skaror öfversvämmade land" . ${ }^{5}$ I huvudstaden kom han att verka som extra ordinarie kanslist vid det kungliga kansliet från år I7II och som en alltmer uppburen skald. Länge tecknade han sig Jacob Frese Viborgensis. De dikter han skrev med anledning av tillfällen som bröllop och begravningar vittnar om att han vårdade vänskaper med dem som kom från hemstaden liksom från Åbo. Till överpostdirektören och kanslirådet Johan Schmedemans minne, "En Man/ hwars Like knapt i Wiborg lärer wakna", skrevs en dikt med anledning av dennes begravning den 8 juni I7ı3, likaså när biskopen i Åbo stift, Johan Gezelius, fördes till den sista vilan den 26 juni I718. ${ }^{6}$

Jacob Frese uppvaktade som nämnt Elsa Magdalena Spieker då hon stod brud. Den dikt som i detta sammanhang är av intresse skrevs till en av hennes systrar, Margareta Catharina Spieker, född I687 i Åbo. Elsa och Margareta var döttrar till handelsmannen Johan Spieker, död I7or, och Catharina Wittfooth som även hon hörde hemma i en burgen köpmansfamilj i staden. ${ }^{7}$ Hennes far Joachim

5. Hultin, "Lefnadsteckning", s. III.

6. Jacob Frese, Andelige Och Werldslige Dikter, Stockholm I726, s. II: 77-79 och 102-104. Kungl. biblioteket, Litteraturbanken, https://litteraturbanken.se/f\% $\mathrm{C}_{3} \% \mathrm{~B} 6 \mathrm{rfattare/}$ FreseJ/titlar/AndeligeOchWerdsligeDikter/sida/-I4/faksimil (hämtad 24/6 202I).

7. Om familjerna Spieker och Wittfooth, se framför allt Raimo Ranta, Ảbo stads bistoria I60o-I72I, Åbo I977; Tor Carpelan, Åbo donatorer intill år 1909. Biografiska anteckningar, Helsingfors I9Io; Tor Carpelan (utg.), Finsk biografisk handbok, del 2, Helsingfors I903, uppslagsord "Spieker, Johan","Wittfooth” och "Wittfooth, Hans"; Valborg Lindgärde \& Görel Cavalli-Björkman,"Äreborne och Dygderika Jungfru Margareta Catharina Spieker. Om en miniatyr och några bröllopsuppvaktningar", Genos. Tidskrift utgiven av Genealogiska Samfundet i Finland 201r:4, s. I45-156. 
Wittfooth (ı620-ı677) var en av Åbos rikaste köpmän, känd liksom dotter och måg för generositet och välgörenhet. Under nödåren i slutet av I60o-talet och de oroliga åren runt I7ıo var insatser av detta slag betydelsefulla. "Tro fritt man utaf hwar mans mund/ | Hör them berömmas margelund [storligen]”, skaldade Jacob Frese vid Elsa Magdalena Spiekers bröllop. Bilden bekräftas i forskningen, exempelvis av Tor Carpelan som beskriver dessa familjer som "ganska förmögna och kända för givmildhet mot kyrka och fattiga". ${ }^{8}$

Catharina Wittfooth begav sig vid denna tid, kanske samtidigt som Jacob Frese, till Stockholm med de båda döttrarna Margareta Catharina och Anna Elisabet. I mantalslängden I7ı för "Maria Magdalena Inre del" finner man dem boende i ett hus som blivit övergivet under den svåra pest som härjade från juli I7ıo till februari I7II och tog en tredjedel av Stockholms befolkning: "Skieppare Carl Iwarsson som med hustrun äro igenom pesten afledne, hwars huus bebos af Kiöppmannen Johan Spijkers änka, hustru Catharina Wittfooth med $2^{\text {ne }}$ sina döttrar, komna från Åbo”. Dessa var på flykt undan fienden, heter det, och i hushållet ingick tre pigor.

Det var många i de namnkunniga släkterna Wittfooth och Spieker som kom till Sverige under stora ofredens första år och bland annat etablerade sig som framgångsrika affärsmän. En bror till Catharina Wittfooth, Hans Wittfooth, stannade dock i Åbo trots oroligheter och förmerade där familjeförmögenheten. ${ }^{9}$ Han figurerar i detta sammanhang som sin systerdotters giftoman, det vill säga förmyndare och den som hade att godkänna äktenskapet eller avstyra det om det av något skäl var olämpligt.

Sven Leijonmarck (I649-I728) var vid denna tid vicepresident i Åbo hovrätt som år I7I3 skulle tvingas flytta till Stockholm för att återkomma först hösten I72r. Han föddes i Uskela prästgård i Finland och dog 1728 på gården Finsta i Skederid, Uppland, en gård som han förvärvat I688. ${ }^{10} \mathrm{I}$ sitt första gifte I680-I692 var han förmäld med

8. Carpelan, Ảbo donatorer intill år 1909, s. 23.

9. Carpelan, Finsk biografisk handbok, uppslagsord "Wittfooth, Hans". Wittfooth dog I732.

Io. Om Leijonmarck, se bl.a. Samuel E. Bring, Bidrag till Sven Leijonmarcks biografi, Uppsala: Almqvist \& Wicksell ı9ı6; Evald Leijonmarck, Adliga ätten nr I092 Leijonmarck, Stockholm [1963]; Stig Jägerskiöld, "Sven Leijonmarck", Svenskt 
Magdalena Adlersköld, dotter till den förmögne fastighetsägaren i Stockholm, kommissarie Lydert Bartels, adlad Adlersköld. ${ }^{11}$ År I696 ingick han ett andra äktenskap, nu med Elisabet Berghult, änka efter tobakshandlaren Croese. I juni I708 avled Elisabet Berghult. Margareta Spieker skulle alltså ha blivit Sven Leijonmarcks tredje hustru.

Om Leijonmarck heter det att han tidigt ägnade sig åt "vittert författande" ${ }^{12}$ I den Palmsköldska samlingen i Uppsala universitetsbibliotek finns fyra dikter som enligt en samtida och trovärdig påskrift är författade av honom. ${ }^{13}$ En av dem är skriven med anledning av Magdalena Adlerskölds begravning. ${ }^{14}$ Denna "Förwanskelighetens Betrachtelse" är enligt titelbladet "Öfwerskickat" till det förnäma "Sorgelaag" som samlades till begravningsakten i Skederids kyrka den 24 juni i692. Trycket kommer från Wankijffs tryckeri i Stockholm men texten kan ha författats av Sven Leijonmarck i tjänst på andra sidan Östersjön. En gravdikt författad av den sörjande maken torde vara ovanligt. ${ }^{15}$

Här, när nu intresset riktas mot exempel ur tidens rikhaltiga tillfällesdiktning, finns det anledning att göra en utvikning. På en av Leijonmarcks "poetiska utgjutelser" - orden är Samuel E. Brings finns nämligen en samtida anteckning som ger en uppfattning om

Biografiskt Lexikon 22, Stockholm I979, s. 498-503.

II. Genom att porträttera tre sondöttrar i detta äktenskap, Maria Magdalena, Elisabeth och Anna Judith Leijonmarck, ger Gudrun Nyberg i Systrar till lärda män. I7oo-tal, Stockholm: Carlssons [2015], s. 63-152, en intressant bild av den tid de levde i.

I2. Jägerskiöld,"Sven Leijonmarck", s. 502.

13. Palmskiöldska samlingen 353, Uppsala universitetsbibliotek (UUB). Samlingen innehåller anteckningar av Elias Palmskiöld som var Leijonmarcks medarbetare i kanslikollegiet och blev hans efterträdare på posten som arkivsekreterare.

I4. Ytterligare en dikt i tryck finns bevarad från detta tillfälle, även den anonym och i kvartoformat. Adlersköld, Verser över enskilda (4:0), I692, Kungliga biblioteket, Stockholm (KB). Den är författad av Sophia Elisabet Brenner och ingår i hennes Poetiske Dikter från I7I3; Sophia Elisabet Brenner, Samlade dikter I:I, Poetiske dikter I7I3. Text, Stockholm: Svenska Vitterhetssamfundet 2009, s. II4, Litteraturbanken, https://litteraturbanken.se/f\%C $3 \%$ B6rfattare/BrennerSE/titlar/SamladeDikter/

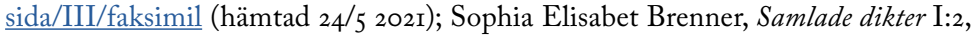
Poetiske dikter I7I3. Kommentar, Stockholm: Svenska Vitterhetssamfundet 2013, s. I27.

15. Ett annat intressant exempel är prästen Uno Troilius sorgedikt över sin hustru Margareta Hansdotter, tryckt i Västerås I657. Se Solfrid Söderlind, "Stormor i Dalom. Karaktär, porträtt, identitet", Personhistorisk Tidskrift (under utg.). 
den funktion en minnesdikt kan tänkas ha haft vid begravningen. På titelsidan av Kungliga bibliotekets exemplar av den dikt som tillkom med anledning av Maria Uttermarcks begravning den 9 april 1685 står att läsa:"Siunges effter den melodi: Såsom effter wattnet kalla”. Bring, som är den som noterar detta, kan hänvisa till det text- och melodisammanhang som avses. ${ }^{16}$ Leijonmarcks"Påminnelse om Menniskians Usle Tilstånd och Werldzens Fåfänglighet" med dess många numrerade verser kan alltså ha sjungits i samband med begravningshögtiden.

\title{
EN DIKT TILL ETT BRÖLLOP ANNO I 7 II
}

\author{
Att Een Leyonmarck i Norden \\ Är til kärlek vptänd worden/ \\ Moot en Pärla fijn och raar, \\ Man medh frögd i dag erfahr.
}

Åter till Jacob Freses dikt med anledning av det planerade bröllopet I7II. ${ }^{17}$ Separattryckets titelsida har överst denna ämnesangivande vers, varpå följer som brukligt adressaternas namn liksom ämbetstitlar, rangordningsbenämningar och - för brudens del - civilstånd. Jungfru Margareta Spieker var alltså ogift, och Sven Leijonmarck var vice president "wid den Högloflige Kongl. Åbo Hoff-Rätt / uthi StorFurstendömet Finland" och därtill den "Wälborne Herren", det vill säga en obetitlad adlig person. Ort - Stockholm - och år för vigseln anges men med plats utsparad för dag och månad. Det som återstår är Anno I7ır. Denna osäkerhetsuppgift återkommer jag till.

Vanligtvis återfinns på tryckets titelsida ett impressum med namn för tryckort och boktryckare. Det saknas här, men typer och överstycket vid dikten säger att skriften är tryckt i det Åbotryckeri som ägdes av

I6. Bring, Bidrag till Sven Leijonmarcks biografi, s. I7-20; för åsyftad psalmmelodi se Johan Wilhelm Beckman, Den Nya Swenska Psalmboken framställd uti Försök till Swensk Psalmhistoria, Stockholm: Norstedts I845, s. 892 med källhänvisningar.

I7. Leijonmarck/Spieker, Verser över enskilda (fol.), I7II, Kungliga biblioteket, Stockholm (KB). Dikten har nr 2037 i Toini Melander, Personskrifter hänförande sig till Finland 1562-I713. Bibliografisk förteckning, Helsingfors universitetsbiblioteks skrifter 22, Helsingfors I95I-I959. Denna dikt nämns och några versrader citeras i Hultin, "Lefnadsteckning", s. XXIV, dock med den felaktiga uppgiften att bröllopet"firades i Stockholm". 
Johan Gezelius d.y. och där Henrik Christopher Merckell var faktor från och med 1707. Det heter i litteraturen att denna dikt var skaldens första kända tillfällesskrift tryckt i Sverige ${ }^{18}$ och det kan möjligen stämma. Under denna osäkra tid lät nämligen Gezelius sommaren I710 flytta tryckeriet med materiel och personal liksom de tryckta arken till Stockholm för att kunna färdigställa sitt bibelverk, den första fullständiga bibelkommentaren på svenska, och det återfördes till Åbo först på sensommaren I7II. ${ }^{19}$

Vad handlar då dikten om? Titelsidans lilla strof summerar som nämnt diktens innehåll, präglat av lek med adressaternas namn. Redan här finns spänningen mellan det exotiska lejonet och "Norden", liksom kontrasten mellan det starka djuret och Margareta, den lilla pärlan,"fijn och raar".

På samma språklekande sätt inleds dikten. Skalden ger först en hyllning till Finland, "Ett Fijnt Land", med en hemhörighet som återkommer i formuleringar som "wåra Marcker" och "wårt Finland". Dikten trycktes måhända i Stockholm men den tillkom redan när Jacob Frese liksom Margareta Spieker och kanske Sven Leijonmarck var kvar i Åbo. Finland är som nämnt" wårt" land, och lejonet, det vill säga Leijonmarck, har kommit "hijt". Det är ett sorgset lejon. Han har nämligen "sin maka mist" och behöver därför muntras upp - "låt oß thet med puß [skämt] til roo vpwäckia". Leijonmarck hade blivit änkeman i juni 1708 , men nu får han syn på den "Ächta Pärlan” och trolovningen med Margareta Spieker kunde efter kungligt tillstånd ingås den ro maj året därpå. "Kom och wäß/ then Pärlan alla fägnar", utbrister skalden med ett inte helt vanligt förstärkningsuttryck. ${ }^{20}$ Denna bröllopsdikt torde ha författats närmare år I709 än I7II.

Dikten präglas av en något haltande vers och ansträngda ordkonstruktioner såsom den aningen sökta namnleken. Som framgått

18. Swahn, Jacob Frese, s. I4.

I9. Carl Rudolf Gardberg, Boktryckeriet i Finland intill freden i Nystad, Helsingfors: Helsingfors grafiska klubb 1948, s. 209-213. Man tvingades göra denna tryckeriförflyttning på nytt, nämligen år I7I3 med verksamhet förlagd till Stockholm ända till fredsslutet I72I. Tryckeriet köptes I7I5 av H.C. Merckel.

20. Min sökning i $S A O B$ (Svenska Akademiens ordbok) var i detta fall förgäves och jag fick skriva till ordboksredaktionen och be om hjälp. Ordet "wäß", blev svaret, kommer av verbet"vädja", och får, ofta i samband med verbet"komma" $i$ imperativ, betydelsen "jag slår vad, jag bedyrar". 
bjuder läsningen motstånd. Att Frese inte tog med dikten i sin samling Werldslige Dickter (I726) har nog inte enbart sin grund i det avlysta bröllopet.

Samtidigt kan man notera att den unge Jacob Frese verkligen bemödat sig. Han var uppenbarligen väl införstådd med Margaretanamnets etymologi, margarita, latinets ord för pärla, och i samråd med tryckeriet hade han förmodligen bestämt att ordet "raar" skulle bli typografiskt markerat i antikva och med mindre stil för att förstärka dess betydelse av sällsynt, kanske med bibetydelsen värdefull och dyrbar. Det är pärlan som är "raar" liksom "thet Leyon raara", det som kommit "hijt".

\section{MEN DET BLEV INGET BRÖLLOP}

I tryck finns alltså en bröllopsdikt i folioformat, tryckt på ett Åbobaserat tryckeri möjligen sedan det på grund av tidens larm och oro tillfälligt flyttat till Stockholm. Men vad var det då som gjorde att detta bröllop inte kom till stånd? Tack vare att trolovningen ägde rum mellan Sven Leijonmarck som adlig person och en ofrälse, fick dess upplösning hanteras i Stockholms konsistorium och handlingar finns därför bevarade och kan ge upplysningar. ${ }^{21}$

Men först ett brev från den kände fornforskaren och konstnären Elias Brenner till den unge greve Gyldenstolpe på gården Noor i Uppland, daterat den 20 mars I7II:

Med Leyonmarcks gifftermål går det mest sälsamt och olyckeligt til, han har uthan communication med bruden och flere wederbörande låtit lysa för sig i Skedere sockenkyrka $[. .$.$] hwilket av henne och$ hennes anhörige illa blifwit uptagit. ${ }^{22}$

Kungligt tillstånd för trolovning hade som nämnt utfärdats den Io maj I709 och vigseln var nu, enligt handlingarna, bestämd att äga rum

2I. E III:59 Handlingar, allmän serie I7II, Stockholms domkapitel, Stockholms stadsarkiv; AI:63 Protokoll, huvudserie I7Io-I7II, Stockholms domkapitel, Stockholms stadsarkiv.

22. Stierneld, (A. L.), Gyldenstolpeska handlingar. F207 Fol. (Uppsala universitetsbibliotek). 
den I6 mars I7ır. Elias Brenner och hans lärda hustru, poeten Sophia Elisabet bodde på Hornsgatan i närheten av Catharina Wittfooth och hennes döttrar, man kan utgå från att de kände varandra och att de jämnåriga döttrarna i de båda familjerna umgicks. Man hade alltså hört om Leijonmarcks obetänksamhet.

Att det planerade äktenskapet "illa blifwit uptagit" även på annat håll framgår av en supplik som ingavs till Kungl. Maj:t den 6 mars detta år. Hans Helding, Leyonmarcks "styfmåg” $i$ hans andra äktenskap med Elisabet Berghult, kräver ytterligare ersättning för kostnader i samband med svärmoderns begravning. ${ }^{23}$ Inget nytt giftermål kan bli av, förklarar han, förrän den krävda summan betalas. Detta ärende slutfördes den II april då det i ett bevittnat protokoll framgår att Helding fått långt mer av sterbhusets egendom än vad honom egentligen tillkommer. Det kunde därmed fastslås att Leijonmarck "må kunna tillåtas utan widare uppehåll sitt påbegynte ächtenskap medelst wigslen at fullborda" och att "intet återstår, som hans ächtenskap til hinder wara kan”.

Men tveksamheten hos Margareta Spieker och hennes familj hade nu uppenbarligen stegrats. Den 28 april noteras ett möte mellan familjen och Lars Eneroth (I68I-I744), vid denna tid hovrättsadvokat, som förde ordet "à jungfru Spiekers och dess moders vägnar”, liksom även med giftomannen, den ovan nämnde morbrodern Hans Wittfooth. Sven Leijonmarck fanns inte på plats vilket innebar att en överenskommelse inte kunde nås. Av senare handlingar framgår att han varit sjuklig.

Troligen var hälsoläget det samma den 15 juli då ärendet uttryckligen var trolovningens upphävande. De sista handlingarna i ärendet är dagtecknade den 25 september och då var även Sven Leijonmarck närvarande.

Ehuruwäl emellan Vice Presidenten i Kongl Hofrätten i Åbo, wälborne he[rr] Sven Leijonmarck och jungfru Margareta Catharina Speker en laglig förlofning skedd är och ächtenskap warit belefwat

23. Hans Helding (I679-I753), år I7I9 adlad Cederstolpe, generalkrigskommissarie, var gift med Agneta Johansdotter Croese (1690-I765], dotter till Elisabet Berghult i hennes första gifte med handelsmannen Johan Croese. 
[godkänt; bestämt] så at de i anseende der til bordt medelst wigsel deras påbegynte ächtenskap fulborda;

"[D]och likwäl" heter det i protokollet som fortsätter "wadan sedermera en sådan kallsinnighet sig yppat, at til befruchtande är, det de inte något godt och förnöjeligit ächtenskap med hwar andra byggia kunna" är det skäligt att upphäva trolovningen och ge dem båda frihet till annat giftermål.

Samtidigt betonades att kontrahenterna fortfarande var vänner även om äktenskapet inte kunde ingås "för den kallsinnighet skull, dem emellan upkommit". Denna upprepade anmärkning om "kallsinnighet" är intressant som ett tungt vägande skäl att avstyra äktenskapet. Möjligen bidrog rådande åldersskillnad på drygt 40 år.

"De togo hwar andra i hand, önskade hwar andra alt godt, och togo der med afträde." Så slutar berättelsen om ett planerat giftermål för vilket det gick, för att citera Elias Brenner,"mest sälsamt och olyckeligt til". Ett litet tillägg i handlingarna kvarstår att notera. Margareta Spiekers familj lovade enligt slutuppgörelsen "ihogkomma fattiga med en hederlig discretion [gåva, gottgörelse]”. Så skedde säkerligen, och det är också här rubrikens tennljusstakar kommer in. De står i dag vid altaret i Skederids kyrka. År I7I8 hade de tillverkats i Stockholm och de skänktes tre år senare till kyrkan av kommissarie Hans Wittfooth, Margareta Spiekers morbror och giftoman. ${ }^{24}$ Man kan förmoda att även dessa ljusstakar var en del av utlovad "discretion".

\section{Hur gick det för Jungfru Spieker, Sven LEIJONMARCK OCH SKALDEN FRESE?}

Margareta Spieker ingick äktenskap den 26 augusti I7ı2 med den mer jämnårige Carl Brander och flyttade till London dit även brodern Johan Spieker kom för att stanna. ${ }^{25}$ Johan Spieker (I685-I775) dog

24. Ingeborg Wilcke-Lindqvist, Skederids kyrka, Upplands kyrkor 88, Uppsala I998, s. I2.

25. Såväl Carl Brander som Johan Spieker blev framgångsrika handelsmän i London. Se kommentar till Sophia Elisabet Brenners dikt med anledning av bröllopet I712 och det brev som hon år I715 avsände till London i Brenner, Samlade dikter I:2, s. 256, resp. 3I3. Se även Lindgärde \& Cavalli-Björkman, "Äreborne och 
som en förmögen borgare i staden utan att lämna några barn efter sig. I testamentet fanns bland annat avsatt en summa till det nya lasarettet i hemstaden Åbo. Men det är en annan historia.

Syskonen Spiekers mor Catharina Wittfooth dog i Åbo I734.

För Sven Leijonmarcks del blev det inget tredje äktenskap. När Åbo hovrätt i samband med freden flyttade tillbaka till Åbo, valde Leijonmarck att stanna kvar i Stockholm."Hans helsa är så, så”, skrev Eric Benzelius till sin bror efter att ha varit på besök i Finsta gård i november I722, men han "arbetar lell [likväl] dag och natt, och är såsom insöfd uti böcker och MSC [handskrifter]". Och Benzelius konstaterar: "Med thenne Gubben, dör mången vacker vettenskap i våra inhemska handlingar." ${ }^{26}$ Leijonmarck hade några år kvar med sina böcker. Han lär ha planerat ett större arbete om Finlands historia. ${ }^{27}$

Med anledning av Leijonmarcks död och begravning I728 författade Jacob Frese, landsmannen, en minnesskrift, tryckt i ståtligt patentfolioformat och utformad i klassisk viator-stil:"Besinna Wandringsman! hwad du för ögon ser”. ${ }^{28}$ Den döde hyllas här för den han i livet var och "hur' han sin wandel förde”. Såväl kung som lärda män har haft honom "högt i wärde", heter det. Detta Epitaphium visar skalden Frese som betydligt mer hemmastadd i skaldekonsten än då bröllopsdikten tillkom. Ett citat gör honom rättvisa:

En GUD, ett Ögneblick, en långer Ewighet

Han sedan fram för alt har giedt sig at betracta;

En GUD, som dålder är, men alting ser och wet:

Et Ögneblick, som kårt; men doch är högt at achta.

En långer Ewighet, på den så sällan tänkes;

Där anten ewigt qwal, ell' ewig Glädie skiänkes.

Dygderika Jungfru Margareta Catharina Spieker”.

26. Brefwäxling imellan ärke-biskop Eric Benzelius den yngre och dess broder, censor librorum Gustaf Benzelstierna; efter originalerne utgifven af Johan Hinric Lidén, Linköping: Tryckt hos F. Schonberg och Björkegrens enka I79I, s. II.

27. Jägerskiöld, "Sven Leijonmarck", s. 502.

28. Leijonmarck, Verser över enskilda (patentfolio), I728, Lunds universitetsbibliotek. Dikten även i Hultin (utg.), Valda skrifter af Jakob Frese, s. I8I. Plats utsparad för begravningsdatum. 
Tidens andliga litteratur tog gärna stilfigurer som antites och paradox i sin tjänst. Slutet summerar i kontrasten mellan ögonblick och evighet diktens budskap och inkluderar därvid alla oss vandrare:

Ach! måtte wij som jämt i säkerhet oß sänka, En GUD, Ett Ögneblick, En Ewighet betänka.

Och hur blev livet för Jacob Frese i Stockholm? Han tjänade sitt levebröd som kanslist i statlig tjänst och blev en uppskattad skald. Men han var sjuklig med en varje vår återkommande frossa, i dag troligen diagnostiserad som malaria."Skal plågan aldrig mer sig skillia från min sida?", utbrast han år $1720 \mathrm{i}$ en dikt, rubricerad ”Då jag åter i Maj Månad föll in i Febren". ${ }^{29}$ Mot slutet av sitt liv, kanske hela tiden, bodde han på Hornsgatan "mit emot Kyrckian", det vill säga inte långt från skaldekollegan Sophia Elisabet Brenner. ${ }^{30}$ År 1729 dör han, ett år innan fru Brenner lämnar jordelivet. Då hade båda vid sidan av ett rikt tillfälleslitterärt författarskap hunnit skriva var sin lång betraktelse på vers över Jesu lidandes historia. Och hela tiden sägs han ha längtat hem till Viborg.

\section{ETT PAR AVSLUTANDE FRÅGOR}

Vem var det som beställde bröllopsdikten som Jacob Frese skrev någon gång i början av år I7ro? Vem bekostade papper, denna bristvara, och tryckning? Det kan ha varit Catharina Wittfooth som säkerligen bidrog till den unge skaldens levebröd då han uppvaktade hennes dotter i januari i71o. Lika troligt är att dikten skrevs och trycktes på uppdrag av Sven Leijonmarck. Om detta vet vi inget.

Inte heller vet vi på vems uppdrag Elias Brenner utförde ett porträtt av Margareta Spieker. Elias Brenner var som Eliel Aspelin, hans biograf, så pregnant sammanfattar det,"en forskare och konstnär från

29. Jacob Frese, Andelige Och Werldslige Dikter, s. I:I7.

30. Uppgiften hämtad ur Andreas Jochim v. Henels adresskalender Den Nu för Tiden florerande Widtberömde Kongl. Residence-Staden Stockholm [...], Stockholm I728, s. 26. 
Karlarnes tid". ${ }^{31}$ Hans forskning ägnades numismatiken och som konstnär blev miniatyrmåleriet ett levebröd. Miniatyren som uttryckligen föreställer Margareta Spieker kan med säkerhet tillskrivas honom tack vare konstnärens egenhändiga namnteckning på boettens baksida tillsammans med den avporträtterades namn och årtalet I7II. Den försåldes den 7 september 2010 av Kaplans auktioner i Stockholm och finns i dag på Finlands Nationalmuseum, Helsingfors. Var den miniatyr som föreställer Sven Leijonmarck och som tillskrivs Elias Brenner i dag finns är oklart. ${ }^{32}$ Det vore naturligtvis intressant att veta om de beställdes vid samma tid och av samma person. Kanske var de tänkta att höra ihop, just såsom Margareta Spieker och Sven Leijonmarck tänktes höra samman. Om inte denna kallsinnighet uppkommit dem emellan.

3I. Eliel Aspelin, Elias Brenner. En forskare och konstnär från Karlarnes tid, Helsingfors: Otava I896.

32. Miniatyren finns avbildad i Bring, Bidrag till Sven Leijonmarcks biografi med uppgiften att den tillhör presidenten Carl Leijonmarck. Enligt Leijonmarck, Adliga ätten $n r$ I092 Leijonmarck, s. 29, kom den i Ingrid och Magda Leijonmarcks ägo, döttrar till Carl Leijonmarck. Efterforskningar har varit resultatlösa. 